\title{
Controlling Thermal Flows through Natural Materials in Building Construction Sector
}

\author{
Simona Colajanni ${ }^{2 *}$, Bartolomeo Megna ${ }^{1}$, Maria La Gennusa ${ }^{1}$, Carmelo Sanfilippo $^{1}$, Dionisio Badagliacco ${ }^{1}$, Marco Bellomo $^{1}$, \\ Antonino Valenza ${ }^{1}$
}

${ }^{1}$ Dipartimento di Ingegneria, Università di Palermo, Viale delle Scienze, 90128 Palermo, Italy

${ }^{2}$ Dipartimento di Architettura, Università di Palermo, Viale delle Scienze, 90128 Palermo, Italy

Corresponding Author Email: simona.colajanni@unipa.it

https://doi.org/10.18280/ti-ijes.632-408

Received: 11 February 2019

Accepted: 20 April 2019

\section{Keywords:}

control heating exchange, building envelope, energy saving, natural material

\begin{abstract}
Nowadays, the attention about the building sustainability is increasingly emerging, because of the major responsibility of the building field on the environmental degradation: both in terms of energy consumption from non-renewable sources and the raw materials impoverishment. In addition, the level of comfort required by users is growing and the thermal insulation of buildings becomes the key element for the reduction of energy consumption and $\mathrm{CO}_{2}$ emissions, both in the case of new construction and of the existing ones. The heat load of a building depends on the presence of insulating material which defines the performance of the building envelope.

The main purpose of this work is both to introduce the production technology of a new ecofriendly Thermo-plaster and to evaluate its thermal insulation performances, also comparing amongst the most diffused insulation materials available in the market. This new technology, on the contrary of other competitor materials, is completely natural and doesn't use any plastic matters.

This new plaster is produced by using a mix of mortar, recycled and natural materials. Amongst the recycled ones we can recall the sawing mud and the glass, among the natural ones we used the Ampelodesmos Mauritanicus (also called diss), which is a perennial plant of the Gramineae family. Increasing the diss fibres percentage improves the thermal benefit. The Proposed plasters have shown thermal performances that can be considered satisfying and competitive compared to other commercially available plasters, analysed through the evaluation of the thermal and dynamics characteristics of four different possible stratigraphic configurations of vertical external walls.
\end{abstract}

\section{INTRODUCTION}

A large part of the Italian building heritage consists of buildings constructed after the Second World War. Overall, it can be estimated that most of the buildings in Italy were built between 1946 and 1991, and 30\% are, from the energy point of view, in very poor conditions.

The buildings built between the fifties and the early nineties, have unsutisfying thermal characteristics because they are often hastily built using poor materials and with little attention to energy saving. Historical and ancient buildings disclose the worst conditions although the massive wall thicknesses compensate for the lack of adequate thermal and acoustic insulation.

On the other hand, it must be noted that a large debate is underway concerning the possibility of equipping historical and old heritage buildings with new systems and technologies [1] that, despite their higher energy efficiency (as explicitly requested by the pertinent EU Directives), are sometimes in contrast with aesthetic perceptions.

In addition, the exploitation of new and innovative components of the building envelope should be encouraged, especially referring to the use of green roofs [2] that, particularly in Mediterranean and warm climates, are supposed to provide significant contribution to the lowering of the energy consumption for the climatization of buildings, at least in the summer season.

The family of new materials appears extremely heterogeneous, the levels at which today it is possible to operate on a single material are many and vary their dimensional scale according to the properties they are intended to confer.

A high energy performance of the buildings can only be reached through the optimization of the building envelope which for the existing structures reflects into the remaking of the plaster.

The majority of the renewable fibers currently used in construction can be used for the production of insulating plasters (thermal and acoustic); in particular, the most commonly used are: hemp, coconut, linen, recycled paper, wood fiber, corn and cork.

The study of new materials with low environmental impact and high performance is one of most recent challenges.

In recent years, an increasingly need to reduce the environmental impact of human work is emerging, limiting the consumption of non-renewable resources and using nonharmful and ecological materials.

The present work is aimed at the characterization of ecosustainable composite materials in the field of green building, for the formulation of insulating plasters and find a solution for the disposal of grass family, Ampelodesma Mauritanicus. 
The use of diss is justified by its high renewability, and sustainability, as well as its interesting physical properties such as low thermal conductivity, low density and a complex chemical structure.

This combination of properties provides characteristics that are difficult to find in other commonly used materials for the formulation of insulating plasters.

The building sector alone consumes about $40 \%$ of resources and has become, over the last fifty years, one of the largest consumers of fossil fuels. About $50 \%$ of the energy produced by these fuels is used for climate control in buildings.

The potential for energy savings is immense, as shown by 'solar' buildings in which solar energy free supplies cover over $90 \%$ of the energy needed for air conditioning-Even the production and processing of building materials have a strong environmental impact as they consume large amounts of clean water and energy and produce considerable quantity of waste, further increased by the debris resulting from demolitions.

The production of certain materials also involves the emission of heavy metals and other toxic substances, greenhouse gases and other gases that destroy the ozone layer in the stratosphere that shields the ultraviolet rays from the sun.

The building activity, concerning large buildings and large infrastructure works, has a strong environmental impact.

What people, like citizens and consumers, must ultimately develop is the sense for the quality of the built that always includes environmental quality.

The most lasting legacy that our generation can leave to the next is not simply a better building heritage, but a new building ethic that recognizes the intense relationship between the built environment and the natural environment [2].

Sustainability, in building project, must not be pursued only by means of materials, sort of correspondence to the criteria of professionalism is required, which can be summarized in the slogan of the "five Rs": "Reduce (materials, energy, water, emissions); Reuse (materials, buildings, soil); Recycle (materials, energy, water); Rebuild (on already built soils); Restructuring / Restoration (areas, buildings, building components)"

Sustainable architecture uses eco-compatible materials which in the production, utilization and disposition stages require the minimum consumption of resources, increasing the quality of life of the inhabitants [3].

This research aims to evaluate the use of Ampelodesma Mauritanicus as an alternative building material to the wellestablished technologies.

The choice of this material is aimed at promoting ecosustainability, trying to create a composite that meets the requirements of mechanical strength and useful thermal performance in construction, while maintaining emissions at very low values.

The aspects of environmental eco-sustainability that should characterize the building materials are identified in the re-use of building materials and their recyclability [4].

All materials and products have an environmental impact, ecological building tries to use those that have lower impact. These impacts do not depend only on the nature of the materials, but also on the adequacy and correctness with which they are used.

The environmental impact also includes the effects exercised on the health of workers and that of those who work and live in buildings. Generally, these are naturally biodegradable substances and work as little as possible. Being ecological for a building material means in fact aiming for a "zero impact". Generally, this means that for both use and manufacturing, which for subsequent disposal, they must require the lowest possible energy consumption by generating as little waste as possible.

Biodegradability is proper to organic substances, but also to some synthetic compounds and represents the property of being decomposed by nature through particular bacteria [5].

\section{MATERIALS AND METHODS}

\subsection{Raw materials}

As the aim of this work is the formulation of an environmentally sustainable insulating mortar, recycled materials i.e Marble Slurry from a quarry located in Custonaci (TP) and Waste Glass from separated collection in Marsala (TP) have been used for the production of a binder with lower energy coupled with the use of natural fibers i.e. Ampelodesmos Mauritanicus as insulating aggregate.

Marble slurry comes from sawing and polishing industries associated with marble quarries in Custonaci, the main sicilian site for extraction of a compact, polishable limestone called "Perlato di Sicilia" a fine mesozoic sedimentary limestone referred to as marble for its technological characteristics. Marble slurry is classified as an industrial waste material, according to Italian laws, and is often disposed as landfill, with some environmental risks [6].

In this work marble slurry was used to produce air hardening lime by kilning and slaking.

Waste glass coming from urban waste collection in Palermo and supplied by Sarco S.r.l. was used to produce a fine powder that could act as pozzolanic aggregate.

Glass powder is studied in literature as a supplementary pozzolanic material, to be used particularly in concrete production [7, 8] or in cement mortars [9].

Ampelodesmos Mauritanicus (diss) is a perennial plant of the Gramineae family, which lives on arid and sandy soils, typical species of the Mediterranean grasslands (Figure 1).

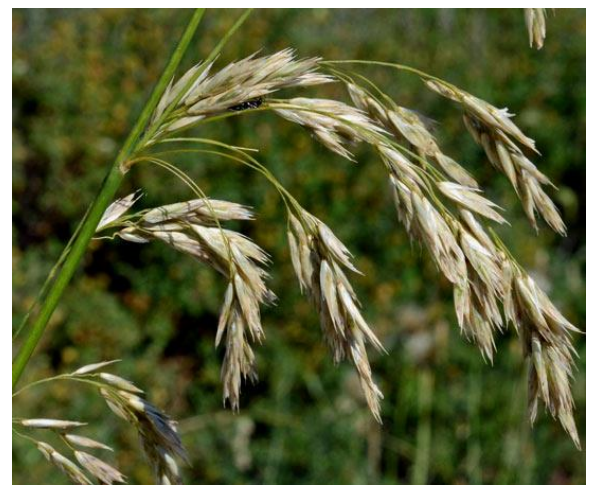

Figure 1. Typical Ampelodesmos Mauritanicus (diss) plant

Native of the Mediterranean climate regions, the species is widespread not only in northern Africa, but also in the coastal areas of Spain, France, the Balkans, Turkey and Asia Minor. In Italy it is present on the arid coastal slopes of south-central Italy, in Sicily and in the coastal area of Liguria (Portofino, Capo Noli, Capo Mele), where the species reach the northern limit of its diffusion in Italy.

Diss is an herbaceous plant of high development with bushy habit. It has resistant leaves, up to $1 \mathrm{~m}$ long and about $7 \mathrm{~mm}$ 
broad, very rough, with later convoluted margins.

Cob on a long and robust culm, richly branched and slightly unilateral, with pedunculate thorns.

The aim of this research is to demonstrate the use of diss as an alternative building material to the well-established technologies.

The choice of this material is aimed at promoting ecosustainability, that is respecting to the environment, trying to create a composite that meets the requirements of mechanical strength and useful thermal performance in construction, while maintaining emissions at very low values.

\subsection{Chemical characterization of the constituents}

Slaked lime putty was obtained by kilning the marble slurry at $900{ }^{\circ} \mathrm{C}$ in a muffle furnace for 24 hours.

So obtained quicklime was slaked with distilled water in a 1:2.5 weight ratio.

The mixture was carefully stirred in order to promote the completion of the reaction for 10 days before preparing of the mortars.

STA, performed after 10 days, showed that $65.36 \%$ of the sample consisted of water; the remaining $34.64 \%$ consisted of $30.79 \%$ of calcium hydroxide and of $2.61 \%$ of calcium carbonate, as shown in Figure 2.

By expressing the results obtained in reference of the dry product it is more correctly to say that the slaked lime consisted of $88.9 \%$ of calcium hydroxide.

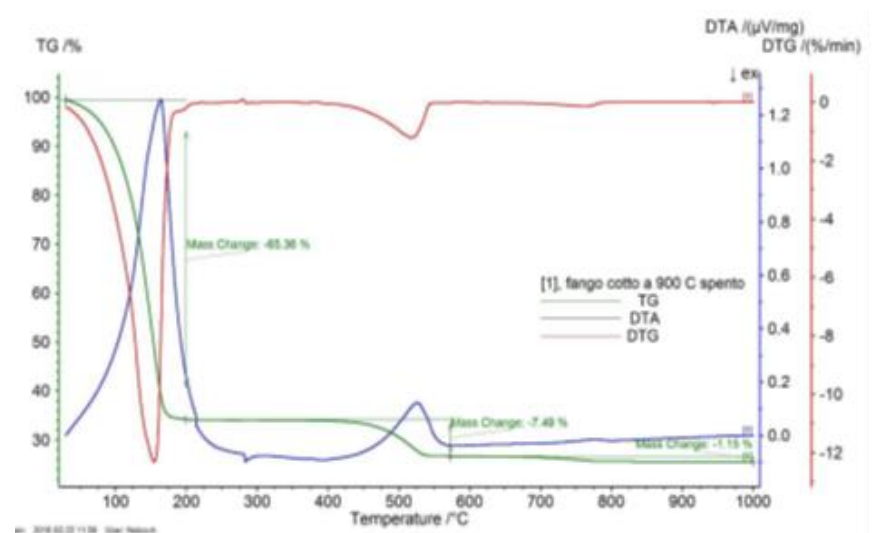

Figure 2. STA of slaked lime obtained by marble slurry

The glass powder provides a pozzolanic activity as the amorphous silica $\left(\mathrm{SiO}_{2}\right)$ can react with lime and forms gels of calcium silicate hydrate $(\mathrm{C}-\mathrm{S}-\mathrm{H})$.

River sand, consisting mostly of quartz with traces of biotite and feldspars (XRD), was used to prepare the mortars. As aggregate, it does not significantly influence the reaction processes but contributes to the mechanical resistance of the finished product.

Diss fibers were analyzed by means of SEM-EDS performed on dry fibers. As shown in Figure 3 diss fibers are characterized by the presence of hooks along the axial directions.

The TGA analysis on the diss shows an $8 \%$ residue after heating the sample to $1000{ }^{\circ} \mathrm{C}$, this means that, there is an $8 \%$ unburnt which, as seen from the SEM analysis (Figure 2), consists mainly of Silica and calcium carbonate.

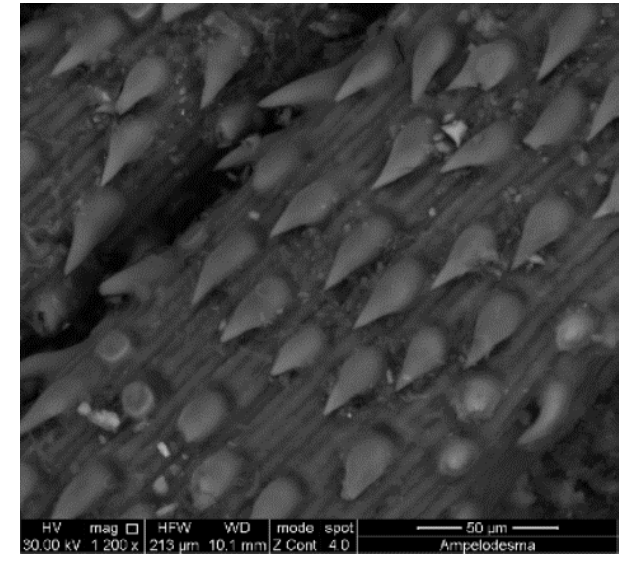

Figure 3. Diss fibers as observed in Secondary electron modes in SEM

The initial $7.9 \%$ is humidity, so we could also say that the residue of ash on the dry is greater, around $8.7 \%$.

\subsection{Thermal characterization of the fibers}

For the thermal conductivity characterization of the fibers a LaserComp FOX314 TA-instruments heat flow meter was used according to the standard ASTM C518.

Table 1. Thermal conductivity of the diss fiber

\begin{tabular}{ccccc}
\hline Fiber type & $\begin{array}{c}\text { Thermal } \\
\text { Conductivity } \\
(\mathbf{W} / \mathbf{m K})\end{array}$ & $\begin{array}{c}\text { Fiber } \\
\text { quantity } \\
\mathbf{( g )}\end{array}$ & $\begin{array}{c}\text { Volume } \\
\mathbf{( c m}^{\mathbf{3}} \mathbf{)}\end{array}$ & $\begin{array}{c}\text { Apparent } \\
\text { density } \\
\left(\mathbf{g} / \mathbf{c m}^{\mathbf{3}}\right)\end{array}$ \\
\hline $\begin{array}{c}\text { Ampelodesmos } \\
\text { mauritanicus }\end{array}$ & 0.059 & 280.4 & 900 & 0.3116 \\
\hline
\end{tabular}

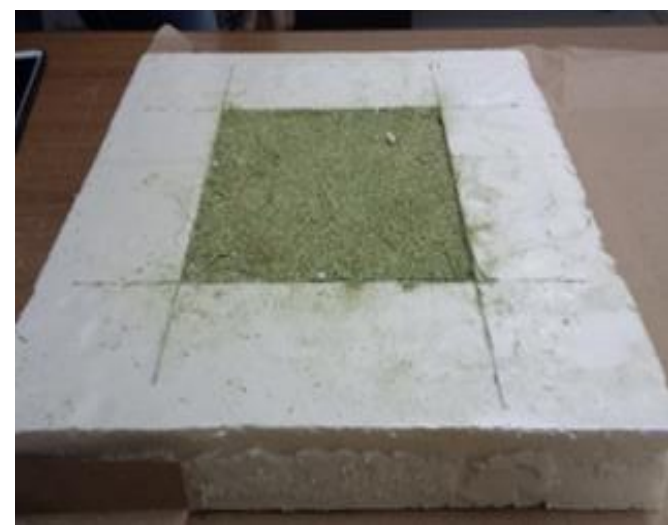

Figure 4. Panel of diss for thermal characterization

From polystyrene panels of size $300 \times 300 \times 40 \mathrm{~mm}$ a square cavity of dimensions $150 \times 150 \times 40 \mathrm{~mm}$ was obtained. It was filled with dried fibers and the panels were wrapped with paper (Figure 4). The values of heat conductivity of the panels were evaluated once reached the steady state of thermal flux between the upper and lower plates set to $25^{\circ} \mathrm{C}$ and $5^{\circ} \mathrm{C}$ respectively. The results of the heat flow meter test of the fibers showed good insulating nature of both the type of plants being the values of thermal conductivity equal to $0.059 \mathrm{~W} / \mathrm{mK}$.

\subsection{Preparation of mortars}

After the thermal fiber characterization, different types of mortars have been prepared by varying the volume of the 
fibers in place of sand as presented in Table 2. The water to binder ratios of all mortar types have been determined according to standards UNI 1015-2 and UNI 1015-3, by means of workability test.

Table 2. Thermal conductivity results of different types of mortars in function of the fiber content

\begin{tabular}{ccc}
\hline Mortar mix & $\begin{array}{c}\text { Volume } \\
\text { Ratio }\end{array}$ & $\begin{array}{c}\text { Thermal } \\
\text { Conductivity } \\
(\mathbf{W} / \mathbf{m K})\end{array}$ \\
\hline V1 - Binder, glass, sand & $1: 1: 2$ & 0,56 \\
\hline $\begin{array}{c}\text { D05 - Binder, glass, sand, } \\
\text { diss }\end{array}$ & $\begin{array}{c}1: 1: 1.5: 0 . \\
5\end{array}$ & 0,53 \\
\hline D1 - Binder, glass, sand, \\
diss & $1: 1: 1: 1$ & 0,39 \\
\hline $\begin{array}{c}\text { D15 - Binder, glass, sand, } \\
\text { diss }\end{array}$ & $1: 1: 0.5: 1$. & 0,27 \\
\hline D2 - Binder, glass, diss & 5 & \\
\hline
\end{tabular}

By varying the fiber ratio in the mix, the best thermal result was obtained by the mortar D2, without sand, characterized by a thermal conductivity of $0.21 \mathrm{~W} / \mathrm{mK}$ (Figure 5 and Table 2).

Table 3. Compression strength by varying the fiber content

\begin{tabular}{ccc}
\hline Mortar mix & $\begin{array}{c}\text { Volume } \\
\text { Ratio }\end{array}$ & $\begin{array}{c}\text { Compression } \\
\text { strength 1 } \\
\text { month (MPa) }\end{array}$ \\
\hline V1 - Binder, glass, sand & $1: 1: 2$ & 2,25 \\
\hline $\begin{array}{c}\text { D05 - Binder, glass, sand, } \\
\text { diss }\end{array}$ & $\begin{array}{c}1: 1: 1.5: 0 . \\
5\end{array}$ & 2,54 \\
\hline D1 - Binder, glass, sand, & $1: 1: 1: 1$ & 1,7 \\
diss & & \\
\hline $\begin{array}{c}\text { D15 - Binder, glass, sand, } \\
\text { diss }\end{array}$ & $1: 1: 0.5: 1$. & 1,20 \\
\hline D2 - Binder, glass, diss & 5 & \\
\hline & $1: 1: 2$ & 1,03 \\
\hline
\end{tabular}

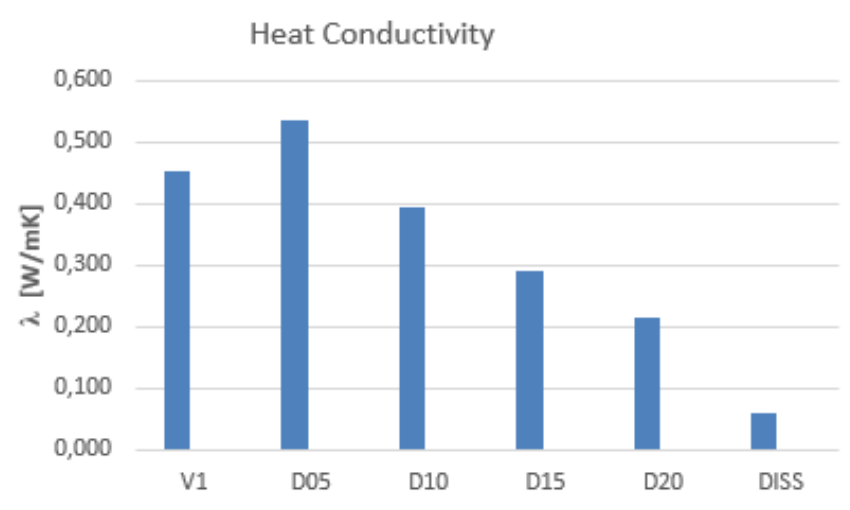

Figure 5. Thermal conductivity by varying the fiber content

\section{COMPARISON BETWEEN THE INSULATION MATERIALS AVAILABLE ON THE MARKET}

To evaluate the research carried out on mortars with natural fibers in the market, we proceeded to simulate the response of a type of comparison for a thermal plaster. The supposed use in the building of plaster with Diss fibers is the application as external or internal thermal plaster for any architectural use, aimed at reducing thermal conductivity. Over the years, the plaster has evolved from a simple finishing and protection material to a wall covering system capable of guaranteeing high performance. The thermal plasters are premixed products specifically formulated to address and solve specific problems of thermal insulation: once applied on the external wall surfaces, they act as an insulating coating, and for this reason they are an optimal solution especially for the recovery of buildings with insulation problems, or in any case where it is necessary to protect the building more effectively against heat loss. Recently, thermal insulation plasters are becoming more widespread: particular types of plaster that, once applied on the building's wall surfaces, create a real insulating layer ensuring, with low thickness, the improvement of the thermal performance of the walls (Figure 5).

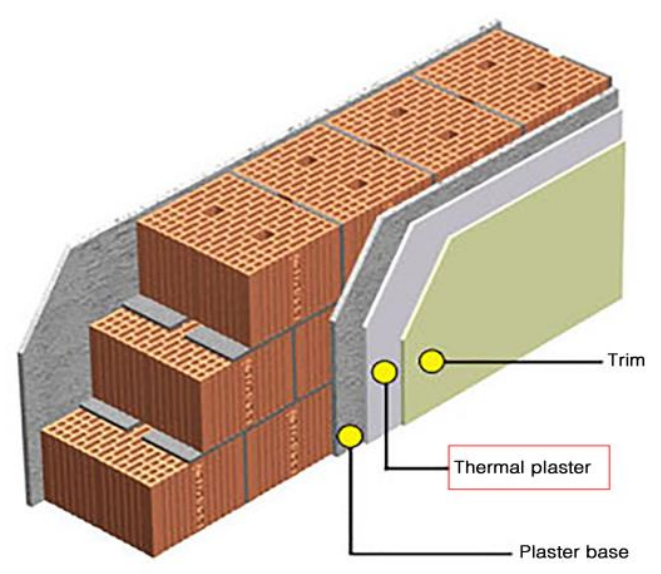

Figure 6. Thermal plaster application scheme

They also allow the effective and simple resolution of the thermal bridges created by the combination of different materials and with different conductivities.

They give the finished plaster a typical microporous structure with good characteristics as well as thermal, also sound-absorbing and fire-resistance. The laying on site is relatively simple and, in any case, no more complex than that of a normal plaster. The thermal plaster fully respects the parameters of protection and thermal inertia of the structures and walls of application. These parameters are, in fact, the basic values that indicate how healthy and liveable is an environment. Also, and above all in the restructuring phase it is necessary to provide a correct thermal insulation protection. In this way energy consumption can be reduced and closer to true energy savings. Furthermore, the application does not require the intervention of specialized personnel, as it does not differ substantially from that of any other plaster. Finally, in the presence of specific needs, the composition of the thermal insulating plasters can be slightly modified so as to offer further performance: this is the case, for example, of fiberreinforced insulating materials, indicated in interventions where a higher mechanical resistance is required for the coating, or even light thermal insulators, suitable for the restoration of walls in restoration works due to their very high yield and low specific weight. The thermal insulating plaster therefore is an excellent alternative to traditional insulating materials, thanks to the following features: Ease of installation, adaptability of the plaster to medium performance of thermal insulation, possibility of reducing the thermal bridges of form and structure (both internal and external).

Thermal plaster is used for the thermal insulation of walls, ceilings and external facades. Optimal solution for new buildings and / or renovations. Suitable for rehabilitation or restoration of degraded facades, to achieve insulation: 
continuous, monolithic and with no leaks. Optimal use in cases of facades where non-uniform thicknesses must be made.

The material we analyzed arises in the building system as a thermal plaster with Diss fibers that is totally recyclable and natural, to be used to improve the thermal and energy characteristics of the building envelope. For a real effect on the market and to be able to buy the natural fiber product with the reality of modern building in terms of energy revaluation interventions, it was decided to compare the plaster with Diss with a white natural lime plaster, a synthetic thermal plaster with eps particles and a natural plaster with cork. In order to have a comparative value in construction, we have a new generation of generic materials in contemporary and modern building, of passive systems integrated in sustainable energy revaluation (Figure 7) [11].

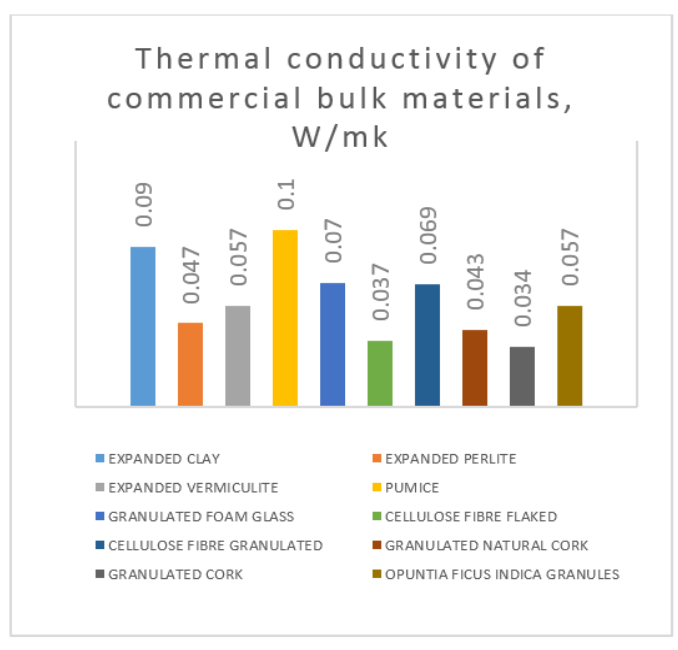

Figure 7. Thermal conductivity of commercial bulk materials

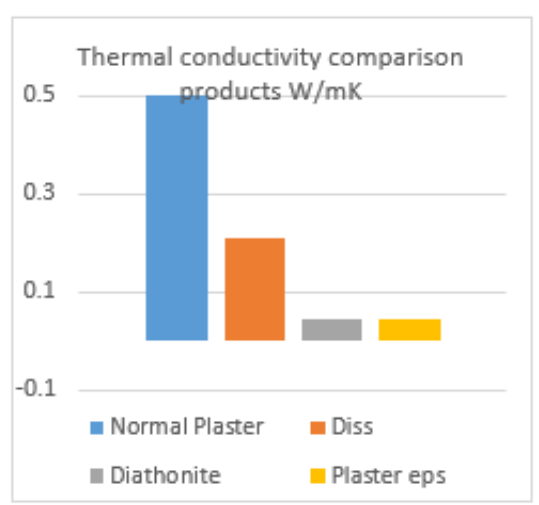

Figure 8. Comparisons on the market of the various products with the analyzed mortars

The comparison with other products on the market was made with mortars with analyzed fibers with the best results and a mortar with cork fibers, a mortar mixed with synthetic fibers, and a simple thermal plaster (Figure 8).

Table 4 shows the main differences between the four identified market forms related to mortars with natural fibers and synthetic fibers.

Table 4. Thermal conductivity comparison products, $\mathrm{W} / \mathrm{mK}$

\begin{tabular}{cc}
\hline Traditional Plaster & $\mathbf{0 . 5 0 2 5}$ \\
\hline Diss & 0.210 \\
\hline Diathonite & 0.045 \\
\hline Plaster with EPS & 0.042 \\
\hline
\end{tabular}

Diathonite is a cork-based spray-applied thermal blanket for indoor and outdoor applications, suitable for thermal insulation and dehumidification. Composed of natural raw materials, the product is designed for historical restoration and green building. this product has an excellent thermal conductivity value compared to those analyzed in fiber, but it is a medium expensive product with the same material. As regards the analyzed synthetic plaster, it is a tested system that foresees the use of expanded polystyrene insulation materials (EPS) for existing buildings and new buildings. The insulating panels are glued to the substrate by an adhesive mortar and, if necessary, further anchored. This synthetic product with eps particles, has excellent results in terms of thermal conductivity but using expanded polystyrene is not a sustainable, recyclable and natural product. All comparison data were taken from product data sheets. The thermal plaster analyzed with natural fibers of Diss totally natural and recyclable, is on the market with thermal conductivity [12] values that lie halfway between a thermal plaster and a mortar with high-performance synthetic fibers.

\section{CONCLUSIONS}

In this research we studied the possibility to use diss fibers as aggregate for the formulation of thermal insulating plasters.

The experimentation carried out in this research allowed to deepen the methodologies and the analyzes necessary for the characterization of the mortars through analytical and experimental approaches. The presence of fibrous organic material gives the possibility of being filled in the whole building cycle. Besides having a quite low thermal conductivity [13] $(0.21 \mathrm{~W} / \mathrm{mK})$, of $0.21 \mathrm{~W} / \mathrm{mK}$ the proposed thermal plaster with the diss fibers has the following advantages:

(1). totally recyclable;

(2). is entirely obtained from natural and waste materials;

(3). e is more eco-sustainable compared to traditional products.

The results of thermal and mechanical tests on samples of diss with 2 and $4 \mathrm{~mm}$ of length and with different percentages in volume, showed that it is more effective to use short fibers, since the thermal conductivity does not change significantly with increasing fiber size while mechanical performance is reduced with increasing length. The best volume percentage is $20 \%$ from a mechanical point of view but not thermal, except that the purpose is to reduce the conductivity, so it was decided to work subsequently with mortars with a percentage of fibers at $30 \%$.

The comparison with the other products has shown how, with a thermal conductivity with an optimal value, the plaster with natural fibers remains the only totally recyclable and sustainable product in the face of a high-performance plaster but with synthetic material and not eco-sustainable.

\section{REFERENCES}

[1] Milone D, Peri G, Pitruzzella S. (2015). Gianfranco Rizzo. Are the best available technologies the only viable for energy interventions in historical buildings? Energy and Buildings 95: 39-46. https://doi.org/10.1016/j.enbuild.2014.11.004

[2] Jones P, La Gennusa M, Peri G, Rizzo G, Scaccianoce G. 
(2016). Vegetation and soil-related parameters for computing solar radiation exchanges within green roofs: are the available values adequate for an easy modeling of their thermal behavior? Energy and Buildings 129(1): 535-548. https://doi.org/10.1016/j.enbuild.2016.08.018

[3] Di Bella G, Fiore V, Galtieri G, Borsellino C, Valenza A. (2014). Effects of natural fibres reinforcement in lime plasters (kenaf and sisal vs. Polypropylene). Construction and Building Materials 58: 159-165. https://doi.org/10.1016/j.conbuildmat.2014.02.026

[4] Germanà ML, Responsabile A, Editore DF, Palermo (2005). cit., pag. 229.

[5] Qualità del costruire con tecniche e materiali biocompatibili-Atti dei seminari di formazione "InBioedilizia" (2002). Edicom Edizioni.

[6] Koenig GK, Furiozzi B, Brunetti F, Ceccarelli G. (2002). Tecnologia delle costruzioni mod.1, Le Monnier, Firenze 162-176.

[7] Mariani E. (1976). Leganti: Aerei e idraulici. Casa
Editrice Ambrosiana 3-21.

[8] UNI EN 459-1: Calci da costruzione-Parte 1: Definizioni, specifiche e criteri di conformità.

[9] UNI EN 197-1: Cemento-Parte 1: Composizione, specificazioni e criteri di conformità per cementi comuni. Ottobre 2011

[10] Mantineo M, D’Agosta GM, Copani V, Patane` C, Cosentino SL. (2009). Biomass yield and energy balance of three perennial crops for energy use in the semi-arid Mediterranean environment. Field Crops Research 114(2):

204-221. https://doi.org/10.1016/j.fcr.2009.07.020

[11] Fassi A, Maina L, Batera FM. (2009). L'isolamento ecoefficiente, guida all'uso dei materiali naturali. Edizioni Ambiente.

[12] Spada C. (2010). Isolanti di origine vegetale, tetto e pareti, Cà Zorzi edizioni, Forlì.

[13] Oleotto E. (2006). Guida agli isolanti naturali. Edicom edizioni, Monfalcone. 